\title{
LIST OF REFEREES
}

The editorial committee wishes to thank the referees.

- Jon Abbink

Leiden University, Leiden, The Netherlands

- Achille Ephrem Assogbadjo

Faculté des Sciences Agronomiques, Université d'Abomey-Calavi, Cotonou, Bénin

- Tom Avermaete

Architecture/Public Building, Delft University of Technology, Delft, The Netherlands

- Emile Boonzaier

University of the Western Cape, Bellville, Republic of South Africa

- Johan De Smedt

Pelckmans, Gent, Belgium

- Hannah Le Roux

University of the Witwatersrand, Johannesburg, Republic of South Africa

- Brice Sinsin

Faculté des Sciences Agronomiques, Université d'Abomey-Calavi, Cotonou, Bénin

- Koen Stroeken

Department of African Languages and Cultures, Ghent University, Belgium

- John R.S. Tabuti

College of Agricultural and Environmental Sciences, Makerere University, Kampala, Uganda

- Patrick Van Damme

Laboratory of Tropical and Subtropical Agriculture and Ethnobotany, Ghent University, Belgium

- Annelies Verdoolaege

Centre for Studies in African Humanities, Ghent University, Belgium

A special thanks to Stéphanie Schaubroeck for helping with the layout of this issue. 